\title{
A produção do discurso em política educacional: lugares e verdades*
}

\author{
Production of speech in educational policy: places \\ and truths
}

\section{La producción del discurso en la política educativa: lugares y verdades}

\author{
Rosimar Serena Siqueira Esquinsani** \\ Jarbas Dametto ${ }^{* * *}$
}

\begin{abstract}
Resumo: A pesquisa em tela problematiza a produção da "verdade" no âmbito das políticas educacionais e indaga sobre os locais de produção e a legitimidade do discurso educacional. Para tanto, este trabalho recorre a uma pesquisa empírica realizada em um conjunto de colunas de opinião veiculadas nos últimos anos, cujo foco temático centrouse em políticas educacionais. Este artigo discute, também, a revisão de alguns conceitos pertinentes de Foucault, bem como estudos recentes acerca da produção acadêmica na área das políticas educacionais, ponderando sobre as suas condições de emergência e a sua aplicabilidade no palco propriamente político. Conclui-se que os discursos pronunciados sobre políticas educacionais carecem de um marco situacional que permita localizar o enunciador e suas circunstâncias, identificando, sobretudo, a origem e as intenções dos discursos extra-acadêmicos que têm participado, acentuadamente, das decisões políticas.
\end{abstract}

Palavras-chave: Políticas educacionais. Discurso. Verdade.

\begin{abstract}
This research discusses the production of "truth" in the context of educational policies, inquiring about the location of production and the legitimacy of the educational discourse. To this end, this work draws an empirical research carried out in a set of opinion columns aired over the last years, whose thematic focus centered on educational policies. This article also discusses the review of some Foucault's relevant concepts, as well as recent studies on academic research in the area of educational policy, pondering their emergency conditions and their applicability in the properly political stage. It is concluded that the speeches about education policy lack a situational framework that allows to locate the enunciator and his/her circumstances, especially
\end{abstract}

\footnotetext{
${ }^{*}$ Financiamento: CNPq, CAPES/MEC/INEP.

** Professora da Universidade de Passo Fundo (UPF). E-mail: <rosimar@pq.cnpq.br>

*** Professor da Universidade de Passo Fundo (UPF). E-mail: <jarbas@upf.br>
} 
identifying the origin and intentions of extra-academic discourses that have participated markedly in political decisions.

Keywords: Educational policies. Discourse. Truth.

Resumen: La investigación presentada problematiza la producción de la "verdad" en el ámbito de las políticas educativas e indaga sobre los espacios de producción y la legitimidad del discurso educativo. Así, este artículo se basa en una investigación empírica llevada a cabo con una serie de columnas de opinión de los últimos años, cuyo eje temático se centró en las políticas educativas. Este artículo discute, también, la revisión de algunos conceptos relevantes de Foucault, así como los estudios recientes sobre la producción académica en el ámbito de la política educativa, ponderando sus condiciones de emergencia y su aplicabilidad en la etapa propiamente política Se concluye que los discursos pronunciados sobre políticas educativas carecen de un marco situacional que permita situar al enunciador y sus circunstancias, identificando, especialmente, el origen y las intenciones de los discursos extra-académicos que han participado, activamente, de las decisiones políticas.

Palabras clave: Políticas educativas. Discurso. Verdad.

\section{Introdução}

[...] o discurso não é simplesmente aquilo que traduz as lutas on os sistemas de dominação, mas aquilo por que, pelo que se luta, o poder do qual nos queremos apoderar. (FOUCAULT, 2002a).

As conquistas sociais e avanços democráticos que se consubstanciaram no Brasil, principalmente a partir da década de 1980, restaram por legitimar, entre outros movimentos, o amplo acesso de camadas populacionais aos bancos escolares, como sinônimo de democracia e de desenvolvimento. Entretanto, na iminência da universalização da educação básica, agiganta-se o debate sobre a relação entre acesso, permanência e sucesso escolar. O acréscimo do número de vagas e a conquista legal do amplo acesso à escola não tem significado exatamente a garantia de qualidade da educação para todos, uma vez que o estímulo ao acesso não tem, necessariamente, conduzido a uma relação simétrica com o êxito escolar.

A relação acesso/permanência/sucesso ainda é claudicante e vem acompanhada pela denominada crise da educação, o que tem favorecido a constituição de um cenário cuja moldura concentra-se em torno dos mais variados espaços de ação e fóruns de debate sobre o assunto. Assim, tal cenário tem projetado duas 
ações de natureza complementar: de um lado, são notórios e elogiosos os esforços de diferentes agentes públicos e privados empenhados para a materialização de políticas que garantam a educação escolar pública a partir de indicadores de qualidade socialmente aceitáveis; por outro lado, há um intenso movimento de debate sobre o tema educação, constituindo uma agenda que perpassa diferentes instâncias, desde o debate centrado no mundo acadêmico, até o debate conduzido no contexto da mídia de grande circulação, direcionado ao público em geral.

Inserido no debate, este texto sugere a problematização do conceito de verdade e de legitimidade da produção do discurso sobre a educação, mormente no campo das políticas educacionais destacando, para fins de problematização, a mídia como produtora de discursos e sentidos sobre a educação. Para consecução do intento estabelecido, o texto foi erigido metodologicamente a partir de uma pesquisa empírica qualitativa em um conjunto limitado de produtos midiáticos: 127 colunas de opinião veiculadas em um dos maiores semanários nacional de variedades, selecionados nos últimos cinco anos, com o foco em discussões e debates sobre políticas educacionais.

Aos excertos da base empírica - apresentada no texto com caráter meramente ilustrativo -, somaram-se reflexões de ordem teórica, no que concerne ao discurso e à produção da verdade, tendo como pano de fundo o pensamento de Michel Foucault (Poitiers, 15 de outubro de 1926 — Paris, 25 de junho de 1984).

Por meio do levantamento empírico proposto, reafirma-se uma espécie de transbordamento de discursos acerca da educação. Evidencia-se a quantidade de reportagens e de colunas de opinião que versam sobre temáticas educacionais. Diversos olhares voltaram-se à educação nos últimos anos, e fica impossível não perceber que, ao fundo desses discursos, se reeditam, por vezes, caducas panaceias, como a fórmula "educação, solução para todos os problemas", por vezes em uma nova roupagem, inversa e alarmista: "educação brasileira, a causa de todos os nossos problemas".

Outro dado que possivelmente desperte a curiosidade de pesquisadores vinculados à área de políticas educacionais é a formação daqueles que falam sobre educação no contexto dos grandes veículos de comunicação de massa: muito frequentemente são economistas, administradores, jornalistas, profissionais liberais, empresários, políticos. Enfim, sujeitos cujos lugares de fala são deveras distintos das realidades vivenciadas pela imensa maioria dos educadores brasileiros, bem como alheios ao local - por excelência e natureza institucional -, de produção desse tipo de saber: os institutos de pesquisas educacionais e os programas de Pós-Graduação em Educação.

Grandes semanários de circulação nacional chegam a ter colunistas especializados em ponderações e em pronunciamentos acerca do tema educação, 
ocupando-se de assuntos cadentes que envolvem, não raras vezes, ações de política educacional. Tais especialistas adotam, em geral, um discurso que carrega um tom acima na crítica encetada, demonstrando, por meio de afirmações fortes e, muitas vezes, prescritivas, uma autoridade incontestável para falar sobre o assunto. Desse modo, parece lícito afirmar que a mídia tem assumido certa proeminência no cenário educacional contemporâneo, seja por divulgar a aplicação e os resultados das avaliações em larga escala, seja por tornar público indicadores educacionais, denunciar a situação da educação nacional, entre outras pautas, fomentando a inclusão de temas e relevâncias na agenda da educação nacional.

Sem desconsiderar a legitimidade de qualquer fórum em que a educação entre em baila, pergunta-se: quem, afinal, pode falar sobre os rumos da educação? Quem teria a legitimidade para fazer isso? Por meio desses questionamentos, pretende-se provocar um debate que extrapola a uma pretensa resposta às questões, resposta esta que, possivelmente, não será satisfatória, mas que pode suscitar discussões que vão além de um direito à verdade, incidindo sobre questões basais dessa área, como as forças que mobilizam a agenda política, o contexto de produção do saber em políticas educacionais, e a solidez das bases epistemológicas que orientam esse campo acadêmico, ou a própria educação como um todo.

Como derradeiro prólogo, cumpre informar que este texto apresenta resultados de uma pesquisa, cujo escopo intenta aproximar-se de elementos de composição da atual agenda educacional, discutindo-os relacionalmente ao papel da mídia na composição dessa agenda.

\section{O discurso sobre políticas educacionais: excertos da empiria}

Considera-se que a mídia tem determinado cada vez mais o ponto de vista das sociedades modernas: "[...] de uma forma profunda e irreversível, o desenvolvimento da mídia transformou a natureza da produção e do intercâmbio simbólicos no mundo moderno" (THOMPSON, 2001, p. 19). O discurso da mídia é ponto determinante na composição da pauta das discussões sociais. O cotidiano brota de suas colunas forjando opiniões e lançando temas aceitos e entendidos como relevantes e dignos de discussão pela sociedade. Ou seja, a mídia é capaz de incluir temas na agenda de debates sociais e, por conseguinte, educacionais, justamente por dar conta "[...] da complexa trama existente entre a linguagem específica em correlação com os sentidos que nela circulam e são construídos, elementos que não se separam do modo de ser e estar, no interior das práticas de produção, veiculação e recepção" (FISCHER, 2002, p. 89), configurando os seus produtos em entendimentos coletivos, em consensos provisórios, em supostas unanimidades. 
A discussão sobre a produção da verdade por meio do discurso da mídia não é, portanto, casuística, uma vez que "[...] as lutas concretas de cada sociedade são postas em cena nos textos da mídia, especialmente na mídia comercial da indústria cultural cujos textos devem repercutir as preocupações da sociedade, se quiserem ser populares e lucrativos" (KELLNER, 2002, p. 32). Nessa perspectiva, foram examinadas 127 colunas de opinião veiculadas em um dos maiores semanários nacional de variedades, no recorte temporal de 2008 a 2012, com o foco em discussões e em debates sobre políticas educacionais. Os produtos midiáticos selecionados para exame alocam-se, assim, na ordem de discurso da imprensa, em que os principais gêneros são: o jornalismo informativo (nota, notícia, reportagem, entrevista) e o jornalismo opinativo (editoria, comentário, artigo, resenha e coluna) (MELO, 1994, p. 62).

Contemporaneamente, a cultura da mídia é responsável pela construção e pela circulação de um amplo leque de imagens, de códigos e de informações. A mídia de massa ainda detém, apesar de uma marcante dispersão do público para mídias eletrônicas não massivas, uma inigualável capacidade de disseminação e de alcance de seus conteúdos e de suas representações acerca da realidade social. Fica claro, portanto, que o impacto social dos conteúdos que ela difunde não pode ser menosprezado.

A mídia possui o condão de determinar a pauta do que será notícia. Assim, a mídia promove certos temas e compõe a agenda do que será discutido (e, por conseguinte, considerado relevante), a partir do momento que prioriza determinados assuntos ou fatos. Ao fazer circular tais temas, constroem-se crenças de que estes são os problemas importantes sobre os quais devemos pensar e nos posicionar. Ao decidir o que será notícia, a mídia também decide, de certa maneira, nossos problemas, inquietações e afeições, gerando um inegável efeito político. Ininterruptamente, os meios de comunicação de massa oferecem modelos sobre o bem e o mal, o certo e o errado, a justiça, a beleza, a política (e as formas de fazê-la), que podem legitimar ou desqualificar determinadas práticas; evidenciar pontos de vista, tornando-os majoritários; e neutralizar ou rechaçar opiniões adversas. Sobre esse assunto Kellner aduz que:

A cultura veiculada pela mídia transformou-se numa força dominante de socialização: suas imagens e celebridades substituem a família, a escola e a Igreja como árbitros de gosto; valor do pensamento, produzindo novos modelos de identificação e imagens vibrantes de estilo, moda e comportamento. (KELLNER, 2002, p. 27).

Assim, os meios de comunicação, de acordo com suas premissas editorias, selecionam e fazem os recortes sobre o que será divulgado (e como o será), o que impinge ao jornalismo um caráter de detentor de sentidos, de produtor de verdades. Todavia, essa produção de verdades está associada diretamente ao público 
potencialmente consumidor daquele discurso, uma vez que "[...] as provas da verdade, ou, melhor dizendo, da veracidade de uma informação são, igualmente, da ordem do imaginário, isto é, baseadas nas representações de um grupo social quanto ao que pode garantir o que é dito" (CHARAUDEAU, 2006, p. 55).

Importa ressaltar que as revistas são tomadas como documentos de domínio público: produtos sociais tornados públicos que,

[...] eticamente estão abertos para análise por pertencerem ao espaço público, por terem sido tornados públicos de uma forma que permite a responsabilização. Podem refletir as transformações lentas em posições e posturas institucionais assumidas pelos aparelhos simbólicos que permeiam o dia-a-dia ou, no âmbito das redes sociais, pelos agrupamentos e coletivos que dão forma ao informal, refletindo o ir e vir de versões circulantes assumidas ou advogadas. (SPINK; MEDRADO, 1999, p. 136).

Por intermédio das páginas de uma revista semanal, exemplarmente, a mídia é capaz de produzir desdobramentos para os seus discursos, consubstanciados em certezas: a formação de opinião. Por meio dos seus discursos sobre os mais diferentes temas, a mídia forma opiniões e condiciona argumentos sobre os temas que lança em pauta.

Dentro do contexto cotidiano, a mídia informativa (como os jornais e as revistas, por exemplo) é especialmente importante, já que ela se torna — direta ou indiretamente - uma fonte essencial de fornecimento dos recursos de que a população dispõe para inserir-se em seu entorno simbólico e nele posicionar-se. Assim, aquilo que tais meios veiculam ou deixam de veicular é significativo do ponto de vista da percepção da realidade social que está disponível para o público consumidor de tais produtos. Essa lógica "informativa" vem no bojo do próprio conceito de jornalismo e dos ideais a partir do qual ele foi inspirado.

[...] o jornalismo é a síntese do espírito moderno: a razão (a verdade, a transparência) impondo-se diante da tradição obscurantista, o questionamento de todas as autoridades, a crítica da política e a confiança irrestrita no progresso e no aperfeiçoamento contínuo da espécie. (MARCONDES FILHO, 2000, p. 9).

Tal concepção gerou a chamada "mitologia da profissão", ou seja, o mito de que o veículo de comunicação (o jornalismo e o jornalista, por conseguinte) é objetivo, imparcial e tem um compromisso com a verdade (SILVA, 2001, p. 9). Já Marcondes Filho (2000, p. 9) soma mais um a esses mitos: o mito da transparência simbioticamente ligado ao mito da isenção. Silva (2001, p. 35) diz, por exemplo, que isenção é o "[...] nome que se dá à opinião que recebe o apoio de um grupo em condição de fazer valer as suas ideias em determinada situação". Todavia, a relação da mídia com o campo da educação é eivada por uma série 
de percalços, argumentos e contra-argumentos que definem, indelevelmente, a agenda da educação no próprio movimento de contradição.

Assim sendo, a mídia é capaz de ratificar estereótipos ou, se assim desejar, produzir sentidos que tragam o tema para o centro do debate social mais amplo, formando a agenda da educação. Como alerta Silverstone (2002, p. 9): "Não podemos escapar à mídia [...] ela está presente em todos os aspectos da vida cotidiana". A mídia, por meio dos seus documentos de domínio público, é capaz de fazer chegar a um maior número de pessoas o debate social acerca da educação nacional, sendo materialmente relevante a apropriação que ela faz sobre as políticas educacionais (ações, intenções ou proposições), atualmente considerado um tema de "moda" no que se refere à totalidade da problemática educacional.

Considerando que os discursos são "práticas que formam sistematicamente os objetos de que falam" (FOUCAULT, 2005, p. 56), o que a mídia veicula e, mais ainda, o que os colunistas ratificados pela mídia apontam assumem um status de verdade que não pode ser desconsiderado.

Os produtos midiáticos analisados foram selecionados apenas de colunas veiculadas, como já mencionado, no recorte temporal de 2008 a 2012. Dentre todas as colunas do período, foram retirados os que tratavam de assuntos genéricos, mantendo-se em situação de exame apenas os que incidiam sobre políticas educacionais no que concernia aos assuntos: ensino/escola pública e educação básica. Com esse recorte, chegou-se a 127 (cento e vinte e sete) produtos midiáticos, cronologicamente assim distribuídos:

Quadro 1 - Distribuição das colunas de opinião por ano do recorte temporal

\begin{tabular}{|c|c|c|c|c|c|}
\hline ANO & 2008 & 2009 & 2010 & 2011 & 2012 \\
\hline Incidência quantitativa & 13 & 18 & 27 & 30 & 39 \\
\hline
\end{tabular}

Fonte: Elaborado pelos autores.

Importante ainda, e para fins de depuração metodológica, informar que a escolha da revista deu-se em razão da alta incidência de colunas que abordam a educação, se comparada com outra revista de igual monta/tamanho e periodicidade.

Para a produção de uma síntese mínima acerca do assunto elaborou-se, inicialmente, um levantamento de aspectos externos sobre as colunas de opinião. Nesse levantamento inicial, constatou-se a diversidade dos temas que são pautados nos produtos midiáticos em tela: qualidade da educação; resultados das avaliações em larga escala; condições de trabalho docente; currículo, aprendizado; escola em tempo integral; financiamento; violência; entre outros assuntos. 
A dinâmica e a fluidez com as quais opiniões sobre a área da educação são colocadas para o grande público pode causar certa inveja nos pesquisadores mais experientes: o mesmo colunista que falou sobre bullying no contexto escolar e sobre políticas de prevenção da violência na semana anterior; na semana seguinte, tece comentários afirmativos e prescritivos sobre a aprendizagem, o financiamento da educação ou a formação de professores. Essa é, aliás, outra característica das colunas de opinião: o uso de argumentos prescritivos e/ou de caráter denunciatório está presente em $100 \%$ dos produtos midiáticos examinados.

Como uma terceira característica geral dos excertos empíricos, é possível destacar a progressiva tematização das políticas educacionais nas colunas de opinião do semanário examinado. De 13 colunas com alguma referência a políticas educacionais em 2008, chega-se, em 2012, a 39 colunas com menção a tal tema. Trata-se de um aumento expressivo, como mostra o gráfico a seguir:

Gráfico 1 - Incidência anual de colunas de opinião tematizando a política educacional

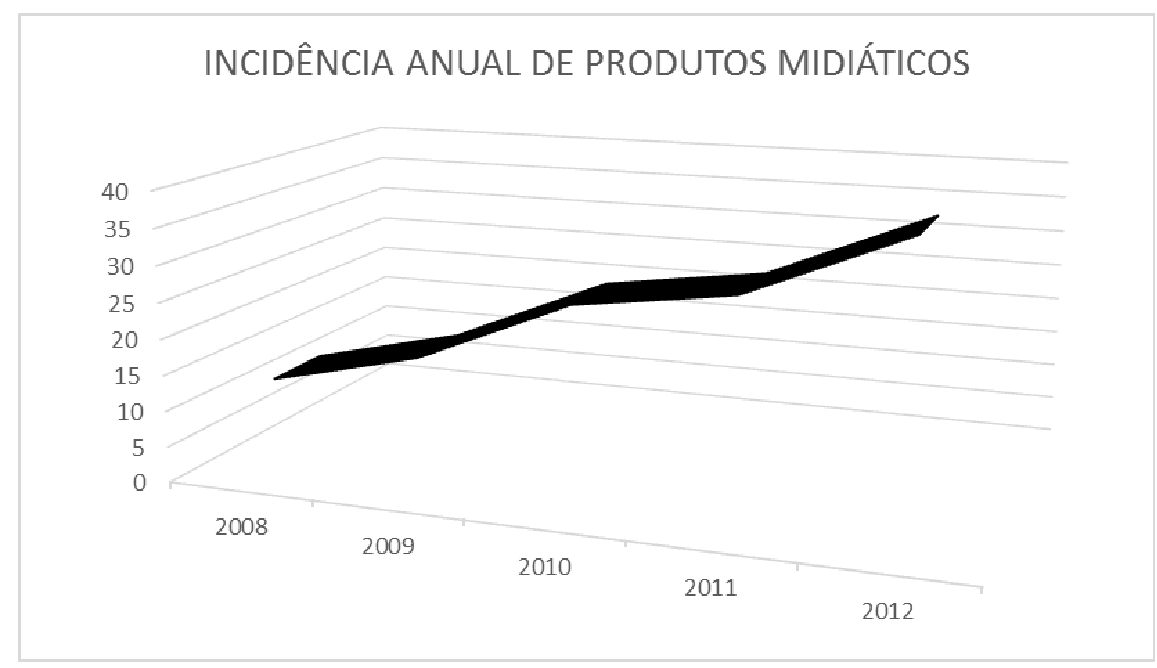

Fonte: Elaborado pelos autores.

Em princípio, o exame linear de tal gráfico permite constatar que, por alguma razão que poderá ser objeto de um estudo posterior e mais acurado, os colunistas de opinião estão, progressivamente, entendendo que devem pronunciar discursos e verdades sobre políticas educacionais.

Sob o ponto de vista do conteúdo, a grande maioria das colunas dedica esforços a dois flancos: ou tecem comentários sobre episódios e situações de pauta ascendente e imediata (como resultados do ENEM ou pesquisas recentemente 
publicadas); ou assumem deliberadamente um tom prescritivo de normatização e fórmulas para/sobre a educação e as ações amplas de políticas educacionais.

Algumas colunas de opinião são prodigas em fomentar certa desconfiança nos leitores consumidores de suas ideias. Essa desconfiança aloca-se, sobretudo, em relação à educação pública brasileira (seus processos pedagógicos e qualidade) e em relação a outros potenciais interlocutores e produtores de agendas para a educação como, por exemplo (e especialmente), a academia.

Não obstante a força da mídia junto ao grande público, o campo políticopartidário também deposita inestimável valor às opiniões prenotadas pela mídia, valendo-se, em muitos casos, dos direcionamentos dados pelos colunistas na hora de pautar suas compreensões e a sua proposição de ações na área das políticas educacionais.

Entendendo que "[...] não há neutralidade na produção de conhecimento, pois todo o processo que envolve conhecimento está atrelado ao intercâmbio material dos homens" (MASSON, 2013, p. 61), o que a mídia publica não pode ser desconsiderado como informação e também como argumento de composição de pauta para agenda educacional, assim como na condição de "verdade" estabelecida para a compreensão de muitos leigos, bem como para o estabelecimento de pautas para a agenda estruturada no campo da educação.

\section{Algumas observações sobre a epistemologia das práticas discursivas}

“Quem está falando?”. Esse questionamento, para além de uma curiosidade recorrente comum a todos que ouvem uma determinada ideia, remete-nos a uma questão central da análise das práticas discursivas, conforme pensada pelo filósofo francês Michel Foucault (1926-1984). Para ele, a verdade institui-se em um espaço polêmico, de conflito e de organização tática, no qual a posição institucional do sujeito que ostenta, reproduz ou promove um discurso ocupa um lugar privilegiado (FOUCAULT, 2005). Logo, essa perspectiva de análise do discurso tem como foco seu caráter estratégico, indo além das regras linguísticas de sua enunciação (FOUCAULT, 2002b). Cabe investigar a organização topológica da prática discursiva, dada sua imersão em uma teia social repleta de lugares de fala, uma ampla diversidade de pontos de apoio e de resistência, um campo de possibilidades e limitações.

Como propõe Fischer (2001), a questão que remete ao status do enunciador pode ser ampliada, revelando a extensão da problemática em questão:

A pergunta "quem fala?" desdobra-se em muitas outras: qual o status do enunciador? Qual a sua competência? Em que campo de saber se insere? Qual seu lugar institucional? Como seu papel se constitui juridicamente? Como se 
relaciona hierarquicamente com outros poderes além do seu? Como é realizada sua relação com outros indivíduos no espaço ocupado por ele. Também cabe indagar sobre o "lugar de onde fala", o lugar específico no interior de uma dada instituição, a fonte do discurso daquele falante, e sobre a sua efetiva "posição de sujeito" suas ações concretas, basicamente como sujeito incitador e produtor de saberes. (FISCHER, 2001, p. 208).

Discursos não emergem ao acaso, assim como, na pretensão de enunciar o verdadeiro, não se pode dizer o que se quer, a qualquer momento e de qualquer lugar. O discurso, assim como o sujeito que o enuncia, está submetido a um princípio de rarefação, atrelado à dinâmica social. Mesmo em uma sociedade em que há ampla circulação de conhecimento e de informação, ocorre a exclusão e a inclusão de sujeitos à ordem discursiva, dando-lhes ou não o direito à enunciação. Isso ocorre porque o discurso é histórico, datado e contextual, fruto de suas condições de produção e difusão.

A produção discursiva é "“[...] ao mesmo tempo controlada, selecionada, organizada e redistribuída por certo número de procedimentos que têm por função conjurar seus poderes e perigos, dominar seu acontecimento aleatório" (FOUCAULT, 2002a, p. 8-9). Em outros termos, não vivemos em um mundo em que a verdade flui livremente. $\mathrm{O}$ discurso não é algo solto, pelo contrário, o direito a enunciação é algo condicionado ao previamente instituído, bem como ao que já é concebido como verdadeiro.

Assim, a resposta para a questão "quem está falando" remete a uma solução orgânica em relação ao enunciado: qual o lugar histórico e circunstanciado de fala do emissor? De quem se trata e com quais ferramentas opera para se pronunciar acerca de determinado tema? Parece que "quem está falando" está proporcionalmente ligado à questão "de onde ele fala?".

As regras que guiam, limitam ou aglomeram o discurso, compõem o que se denomina "formação discursiva", que são redes complexas de relações que existem dentro de campos do saber que lhe atribuem certa regularidade e, também, certa exclusividade. Trata-se de um sistema de formação que "[...] prescreve o que deve ser correlacionado em uma prática discursiva, para que esta se refira a tal ou tal objeto, para que empregue tal ou tal enunciação, para que utilize tal ou tal conceito, para que organize tal ou tal estratégia" (FOUCAULT, 2005, p. 82-83).

De um modo geral, cada campo do saber possui seu léxico próprio, seus lugares-comuns, suas práticas discursivas ou extra-discursivas familiares a todos que passaram pelo crivo iniciático, via de regra universitário, e que compartilham de seu contexto. Como aponta Fischer (2001), trata-se de uma "matriz de sentido" em que os falantes reconhecem-se dada a obviedade e a naturalidade com que são percebidas as significações correntes em cada campo de saber. 
As "coisas ditas", portanto, são radicalmente amarradas às dinâmicas de poder e saber de seu tempo. Daí que o conceito de prática discursiva, para Foucault, não se confunde com a mera expressão de ideias, pensamentos ou formulação de frases. Exercer uma prática discursiva significa falar segundo determinadas regras, e expor as relações que se dão dentro de um discurso. (FISCHER, 2001, p. 204).

Na leitura foucaultiana, o discurso é o campo em que se constitui o verdadeiro, que não diz respeito aos acontecimentos ou as coisas, tal e qual são, mas sim ao que desses fenômenos pronuncia-se, seguindo a regras específicas de determinada cultura e momento histórico e, principalmente, de determinados campos do saber (FOUCAULT, 2002a). O sentido, nessa perspectiva, não é extraído da realidade, as verdades não são fiéis representações dos fatos, são sim acontecimentos que remetem às relações de poder e saber que permeiam toda a sociedade.

Temos que admitir que o poder produz saber (e não simplesmente favorecendo-o porque o serve ou aplicando-o porque é útil); que poder e saber estão diretamente implicados; que não há relação de poder sem constituição correlata de um campo de saber, nem saber que não suponha e não constitua ao mesmo tempo relações de poder. (FOUCAULT, 1984, p. 30).

Tais considerações remetem-nos a uma análise crítica das práticas discursivas impetradas na sociedade moderna, expondo a natureza política da verdade. De um modo geral, não podemos afirmar que tal panorama mudou, que hoje o discurso e a verdade estão desatrelados do poder e de suas bases institucionais. Pelo contrário, nas últimas décadas, intensificaram-se as regulações, principalmente naquilo que concerne às disciplinas científicas e técnicas: a precisão conceitual e a coerência epistemológica e metodológica vêm sendo solicitadas para atestar a validade do discurso científico das mais diversas áreas. Como nos propõe Foucault:

A verdade é deste mundo; ela é produzida nele graças a múltiplas coerções e nele produz efeitos regulamentados de poder. Cada sociedade tem seu regime de verdade, sua 'política geral' de verdade: isto é, os mecanismos e as instâncias que permitem distinguir os enunciados verdadeiros dos falsos. (FOUCAULT, 2002c, p. 12).

Curiosamente, e é esse aspecto que incita o presente artigo, o campo educacional como um todo - e em especial o campo das políticas educacionais -, parece não participar desses princípios de regulação do discurso. Com exceção de parte do que é publicado em âmbito acadêmico, a maioria daquilo que é dito, seja na mídia geral, em livros com temas educacionais ou em eventos dirigidos aos próprios educadores, comumente foge a qualquer ordenação discursiva: não 
se trata de um discurso propriamente pedagógico ou educacional, mas sim de alguém falando sobre educação, de qualquer lugar, com qualquer léxico, com qualquer formação. Mas, paradoxalmente, tais discursos, mesmo com tais características, não deixam de provocar efeitos atribuíveis a uma verdade, como o consentimento, as mudanças nas agendas políticas, as mudanças de conduta ou de visões de mundo, ou seja, tais discursos, mesmo desconectados com uma suposta "política geral do discurso do campo educacional", geram efeitos práticos na vida dos sujeitos envolvidos.

Frente a tais observações, cabe traçar mais alguns questionamentos: qual o local de emergência da verdade no discurso sobre política educacional? Seria esse local a escola, a academia, os grupos e os centros de pesquisa, a sociedade como um todo? E, ainda, qual a política de verdade da educação? Como reconhecemos o verdadeiro do falso nos discursos sobre a prática educativa? Sua inevitável interdisciplinaridade e polissemia lançaria o campo educacional "nas mãos de todos"? Ou, em termos menos polidos, "nas mãos de qualquer um"? Ou temos visto, efetivamente, uma invasão desse domínio por meio de um grosseiro direito de fala, oriundo meramente de uma estrutura econômico-midiática, hoje em vias de se tornar anacrônica, em que perdura uma espécie de monopólio da enunciação, paradigma que permeou os meios de comunicação de massa durante todo o século XX?

\section{Atributos da produção do saber/discurso em políticas educacionais no Brasil}

Em relação ao discurso da mídia e às opiniões emitidas/formadas, qual o processo que a produção científica tem tracejado para dar conta dos discursos e das pesquisas no campo da política educacional? Com base em tentativas de resposta a essa questão, podemos equacionar argumentos que favoreçam um contraponto crítico ou que discutam como a academia tem respondido - do seu lugar e com suas pesquisas -, ao discurso e as verdades da mídia, uma vez que se parte da premissa que a pesquisa científica, mormente no campo da política educacional, tem como escopo a aproximação circunstanciada de ações e de contextos em que efetivamente se desenvolve a política educacional.

Entretanto, Barretto (2009) alerta que a pesquisa no campo das políticas educacionais no Brasil sofre uma marcante dispersão por serem desenvolvidas, em sua maioria, por discentes de pós-graduação, que operam em condições de financiamento precárias ou inexistentes, bem como com prazos que forçam a opção por pesquisas de menor amplitude. Além disso, seguindo em sua crítica, a autora afirma que as pesquisas em geral não se aprofundam "[...] no exame das condições histórico-específicas em que as políticas se transformam em cursos 
de ação" (BARRETTO, 2009, p. 4). De outra maneira, autores como Mainardes (2009) chamam a atenção para problemas de esfera teórica e metodológica em pesquisas sobre as políticas educacionais. Ainda, sobre essa questão, Krawczyk (2012) ajuíza que, desde a década de 1960:

A institucionalização da pesquisa, conjuntamente com a institucionalização da pós-graduação em educação, diferentemente de outros países, trouxe como consequência uma forte associação entre atividades de formação e de produção de conhecimento; e, principalmente, a burocratização do trabalho científico, o que se reflete no que poderíamos denominar de escolarização da produção científica. Por isso, é comum encontrar produções acadêmicas associadas a diplomas, determinada por uma organização e um formato que expresse os requisitos institucionais e os tempos preestabelecidos. (KRAWCZYK, 2012, p. 4).

Nas palavras de Krawczyk (2012), a pesquisa e a produção de conhecimento em políticas educacionais no Brasil, desde sua origem na década de 1940, sempre esteve atrelada aos fenômenos sociais, políticos e econômicos em âmbito nacional ou internacional. Em geral "[...] as macrodecisões sobre as políticas educacionais são tomadas com base em referenciais que provêm, frequentemente, de outros campos do saber" (BARRETTO, 2009, p. 4) ou, como pondera outra autora, “[...] as contribuições teóricas e metodológicas advindas da antropologia, da sociologia e da ciência política, sobretudo, foram fundamentais para a incorporação de muitos (re)desenhos na área da educação" (MARTINS, 2011, p. 308).

A pesquisa, nesse âmbito, institui-se como uma forma, ora de referendar e dar suporte a tendências macropolíticas predominantes em um dado contexto histórico, ora de contrapor tais tendências, como uma forma de resistência e de crítica a propostas hegemônicas. Ainda como constituição de uma crítica mínima, parece haver uma dicotomia entre os estudos de natureza teórica e os estudos de caso, centrados em ações contextuais e históricas, levando a se "[...] interrogar em que medida os estudos de natureza teórica têm contribuído para a análise de políticas específicas e ainda como e em que medida os estudos de políticas específicas têm incorporado as contribuições do primeiro grupo (estudos de natureza teórica)" (MAINARDES, 2009, p. 7).

Além do mais, pontuam os autores utilizados, são raros os estudos em políticas educacionais que "[...] procuram relacionar resultados e políticas de âmbito geral. O mais comum é que a abordagem, seja ela no âmbito federal, estadual ou local, ocupe-se de grande variedade de objetos, sendo ainda tênue o esforço cumulativo capaz de adensar as temáticas exploradas" (BARRETTTO, 2009, p. 3). Pode-se presumir que essas lacunas e dispersões restam por permitir que opiniões de senso comum - ou baseadas em um conhecimento que pode ser parcial 
ou ancorado em práticas advindas de campos alheios ao âmbito educacional -, sejam forjadas para dar conta de fenômenos educacionais, em especial para explicar e analisar políticas públicas voltadas à área da educação brasileira.

Como não há um suficiente acúmulo de conhecimento em relação a determinados temas - uma vez que políticas educativas na América Latina ainda são um campo em construção, considerando que as investigações ainda carecem de referenciais analíticos consistentes e uma definição mais clara do objeto de investigação (MASSON, 2013, p. 56), bem como ostentam uma polissemia epistemológica -, qualquer enunciado produzido de forma fragmentada passa a ser o indicativo confiável de interpretação sobre o fenômeno, permitindo a emissão de opiniões retoricamente convincentes, que incidem, principalmente no grande público, como verdades dignas de crédito. De outra feita, as políticas educacionais são orgânicas, contextuais e históricas. Justo por essa razão, não tem uma trajetória linear e evolutiva, mas são circunscritas aos sujeitos que são afetos por elas.

Cabe ponderar que os pesquisadores em políticas educacionais, por via de regra, são pessoas que elaboram análises e críticas acerca das políticas, porém não são os agentes que elaboram, implantam e avaliam as ações. O campo político e o campo acadêmico não são alheios um ao outro, pelo contrário, mostram uma marcante imbricação, como aponta Krawczyk (2012). No entanto, são espaços de ação diferentes, que obedecem a coerções discursivas e extra-discursivas distintas. Enquanto o campo propriamente político tem como balizador o interesse público, ou mais superficialmente, a opinião pública, suas demandas e suas pressões, bem como pressões oriundas de interesses classistas ou particulares; a academia precisa dar conta de um campo conceitual pré-existente, de uma filiação teórico-metodológica válida, de um léxico que lhe é particular.

[...] os pesquisadores, de um modo geral, desenvolvem pesquisas com o objetivo de compreender uma determinada política ou um conjunto de políticas e, ao fazer isso, oferecem ideias e elementos que poderiam ser úteis na formação ou reorientação de políticas. No entanto, a realização de pesquisas com o objetivo específico de instrumentalizar decisões políticas pode restringir a autonomia dos pesquisadores acadêmicos. A esse respeito, Paiva (1998) faz um alerta relevante ao indicar que o tempo, intenções e finalidades são diferentes para os gestores do sistema e para os pesquisadores. (MAINARDES; FERREIRA; TELLO, 2011, p. 151).

Se há (e parece crível que haja) um descompasso de tempos e de intenções entre as necessidades de gestores e os objetivos científicos de pesquisadores, quem ganha campo e legitimidade na composição da pauta da sociedade e dos gestores públicos - sempre ávidos por respostas urgentes e soluções imediatas 
ou de alto impacto -, é a mídia, a qual ocupa esse espaço do seu lugar de produção do discurso e da verdade.

\section{Considerações finais}

A "verdade" da política educacional não pertence à academia tampouco nela se localiza com exclusividade. Também é temerário localizá-la de maneira isolada nas ações que correspondem às políticas educacionais, como algo a ser descoberto e examinado pelo olhar do pesquisador. Como propõe Foucault em parte das ideias acima revisadas, as verdades não estão à espera de sua descoberta, elas são consequência de arranjos complexos. De igual maneira, também é arriscado balizar avaliações sobre política educacional de forma acrítica a partir de opiniões expressas em colunas midiáticas.

Antes, a verdade é discurso, um discurso que efetivamente extrapola os limites da ciência, que se organiza estrategicamente e empreende permanente conflito. E o discurso é uma produção humana e não reflexo opaco de um saber puro a ser um dia conquistado, tal qual pensado desde a tradição platônica. Assim, a forma assumida pelo discurso, entendido como "um conjunto de enunciados que se apoiem na mesma formação discursiva" (FOUCAULT, 2005, p. 135), não é (e nem poderia ser) apenas um espaço semântico, nem um mero esforço lógico e cognitivo, mas uma condição indexada com o contexto de sua enunciação, sua materialidade, bem como com a polêmica estabelecida na imbricação com outros discursos que lhe avizinham.

Interessante sinalizar, diante dessa constatação, que ao pesquisador em políticas educacionais cabe tratar os discursos sobre os rumos da educação emitidos nos grandes meios de comunicação ou em outros contextos não acadêmicos como mais um fenômeno político digno de análise, que participa da formação das agendas políticas em educação ou delas emerge como um efeito. Quando se fala dos rumos da educação, partindo de pontos de ancoragem alheios a ela, tem-se propriamente uma luta pelo direito à verdade, e o anseio de que tal dizer ecoe em dimensões práticas.

Por fim, considera-se que os diversos discursos pronunciados sobre políticas educacionais, mormente no que tange aos rumos da educação nacional, carecem de um marco situacional que permita localizar o enunciador e suas circunstâncias, bem como - e em função de uma dispersão epistemológica que lhe é típica -, de um arrazoado crítico que permita identificar a origem e as intenções dos discursos extra-acadêmicos que participam, acentuadamente, das decisões políticas. 


\section{Referências}

BARRETTO, E. S. S. Perspectivas teóricas e metodológicas da pesquisa em política educacional na atualidade. Estudos em Avaliação Educacional, São Paulo, v. 20, n. 44, p. 493-506, set. / dez. 2009.

CHARAUDEAU, P. Discurso das mídias. Tradução de Ana M. S. Corrêa. São Paulo: Contexto, 2006.

FISCHER, R. M. B. Problematizações sobre o exercício de ver: mídia e pesquisa em Educação. Revista Brasileira de Educação, Rio de Janeiro, n. 20, p. 83-94, maio/ago. 2002. DOI: 10.1590/S1413-24782002000200007

FISCHER, R. M. B. Foucault e a análise do discurso em Educação. Cadernos de Pesquisa, São Paulo, n. 114, p. 197-223, nov. 2001. DOI: 10.1590/S0100-15742001000300009

FOUCAULT, M. Vigiar e punir. 3. ed. Petrópolis: Vozes, 1984.

FOUCAULT, M. Microfísica do poder. 17. ed. Rio de Janeiro: Graal, 2002a.

FOUCAULT, M. A verdade e as formas jurídicas. 3.ed. Rio de Janeiro: Nau, 2002b.

FOUCAULT, M. A ordem do discurso. 8. ed. São Paulo: Loyola, 2002c.

FOUCAULT, M. A arqueologia do saber. 7. ed. Rio de Janeiro: Forense Universitária, 2005.

KELLNER, D. A cultura da mídia - estudos culturais: identidade e política entre o moderno e o pós-moderno. Bauru, SP: EDUSC, 2002.

KRAWCZYK, N. A historicidade da pesquisa em política educacional: o caso do Brasil. Jornal de Políticas Educacionais, Curitiba, v. 6, n. 12, p. 3-11, 2012.

MAINARDES, J.; FERREIRA, M. S.; TELLO C. Análise de políticas: fundamentos e principais debates teórico-metodológicos. In: BALL, S. J.; MAINARDES, J. (Orgs.). Políticas Educacionais: questões e dilemas. São Paulo: Cortez, 2011. p. 143-172.

MAINARDES, J.; MARCONDES, M. Entrevista com Stephen J. Ball: um diálogo sobre justiça social, pesquisa e política educacional. Educação \& Sociedade, Campinas, v. 30, n. 106, p. 303-318, jan./abr. 2009. DOI: 10.1590/S0101-73302009000100015

MAINARDES, J. Análise de políticas educacionais: breves considerações teóricometodológicas. Contrapontos, Itajaí, v. 9, n. 1, p. 4 -16, jan./abr. 2009.

MARCONDES FILHO, C. Comunicação e jornalismo: a saga dos cães perdidos. São Paulo: Hacker editores, 2000.

MARTINS, A. M. A Pesquisa na área de política e gestão da Educação Básica: aspectos teóricos e metodológicos. Educação e Realidade, Porto Alegre, v. 36, n. 2, p. 379-393, maio/ago. 2011.

MASSON, G. Orientações para o desenvolvimento de investigação em políticas educativas a partir da teoria marxista. In: TELLO, C.; ALMEIDA, M. L. P. (Org.). Estudos epistemológicos no campo da pesquisa em política educacional. Campinas, SP: Mercado de Letras, 2013. p. 55-76.

MELO, J. M. de. A opinião no jornalismo brasileiro. Petrópolis: Vozes, 1994. 
SILVA, J. M. A miséria do jornalismo brasileiro: as (in) certezas da mídia. 2. ed. Petrópolis: Vozes, 2001.

SPINK, M. J.; MEDRADO, B. Produção de sentido no cotidiano: uma abordagem teóricometodológica para análise das práticas discursivas. In: SPINK, M. J. P. (Org.). Práticas discursivas e produção de sentidos no cotidiano. São Paulo: Cortez, 1999. p. 41-61.

THOMPSON, J. B. A mídia e a modernidade: uma teoria social da mídia. 3. ed. Petrópolis: Vozes, 2001.

Recebido em 30/11/2013

Versão corrigida em 05/04/2014

Aceito em 17/04/2014 